\title{
STRUCTURE, CHARACTERIZATION AND APPLICATION OF NI HYDROTALCITE AS SOLID BASE CATALYSTS FOR ORGANIC TRANSFORMATIONS
}

\author{
ATEEQ RAHMAN*AND SALEM S AL-DEYAB \\ College of Science, Petrochemical Research Chairl, Department of chemistry, Post Box-2455, King Saud University, Riyadh-11451, \\ Kingdom of Saudi Arabia.
}

(Received: December 29, 2009 - Accepted: January 26, 2011)

\begin{abstract}
$\mathrm{Ni}$ hydrotalcites with different kinds of metals, ions exhibit considerable activity for organic transformations. Various ratios of Ni-Al hydrotalcites are prepared by using different compositions are characterized by XRD, IR and TPR analysis. Carbonate in the brucite sheets is active for selective oxidation reactions. Upon calcination the dehydroxylation of the hydrotalcite and concurrent decomposition of the carbonate ions produce mixed oxides which exhibits activity for variety of organic transformations.
\end{abstract}

Keywords: Hydrotalcite, LDHs, mixed oxides, structure.

\section{INTRODUCTION}

Heterogeneous catalysts have many advantages such as easy separation and reusability. The efficient catalyst have many economic benefits such as ease of catalyst recovery, low cost, recycling, zero emission of pollutants, longer life time. Till 1970 the research into the catalysis, and hydrotalcites were followed in parallel paths then the first patent which was referred to as hydrotalcite was prepared for the use in hydrogenation reactions [1]

Hydrotalcite, which is a mineral white crushed into fine powder and first discovered in Sweden around 1842 as a hydroxy carbonate of magnesium and aluminium which occurs in nature in foliated and contorted plates. The first formula of hydrotalcite was presented by Professor Mannase, at the University of Florence [2].

The hydrotalcites are classified as Cationic or Smectite type in which the layered structures are arranged in sheets as brucite type $\mathrm{Mg}(\mathrm{OH})_{2}$ and $\mathrm{Al}(\mathrm{OH})_{2}$ octahedral separated by charge balancing anions, water and these occupy the interlayer spaces. The sheets then stack (in the crystallographic c direction) to give a characteristic layered material. In many samples of hydrotalcite, few of the $\mathrm{M}^{2+}$ species are substituited by $\mathrm{M}^{3+}$ species, which results into the layers carrying the residual positive charge. Crystals of hydrotalcite which mostly consists of micron sized stacks of hexagonal platelets morphologically. However, fibrous and extended sheet-like morphologies is reported depending upon the conditions of synthesis [4-5]. Thermal calcination of these materials results in the formation of non-stoichiometric mixed metaloxides with characteristic properties, which are extremely active catalysts for many important transformations. Various catalytic applications of htlc are such as steam reforming, methanol and higher alcohol synthesis [6], selective oxidation of alcohols to aldehydes [7], and reduction of aldehydes to alcohols [8], epoxide ring opening [9], epoxidation [10], Aldol condensation [11], cyanoethylation [12], Micheal reaction [13], and transterification [14]. Pinnavaia [15] and co-workers reported excellent work on intercalation of polyoxometallates as anion pillars and exploited them in selective oxidation reactions [16]. During the past decade strong impetus was given to modify these materials for the synthesis of fine chemicals, exploring both basic and redox properties. Recently Choudary et al [17] reported oxidative bromination of bisphenol-A excellent activity for osmate intercalated hydrotalcite for asymmetric dihyroxylation of various aliphatic and aromatic olefins [18] using NMO (N-methylmorpholine N-oxide) as co-oxidant. The maximum amount of water present in the interlayer can be calculated on the basis of sites present in the close packed configuration of oxygen atoms, as discussed here Kannan [19] reported intercalation of metallophthallocyanine tetrasulfonate in the intergallery of $\mathrm{Mg}$-Al hydrotalcite which is synthesized by different routes. Many variations in compositions are reported for hydrotalcites. Hydrotalcite catalysts are prepared by different co-precipitation methods depending upon the composition of the $\mathrm{M}^{2+}$ and $\mathrm{M}^{3+}$ [20]. Choudary et al [7] reported $\mathrm{Ni}-\mathrm{Al}$ hydrotalcite is prepared by the above said methods. Ni-Al hydrotalcite with varied composition of Ni-Al hydrotalcites $(\mathrm{Ni}: \mathrm{Al}=2: 1$ (cat. A), 2.5:1, 3:1) were prepared with co precipitation technique by employing $\mathrm{NaOH} / \mathrm{Na}_{2} \mathrm{CO}_{3}$ as described in the literature [20-22]. Dr Choudary and group [7-14, 17-18, 21] who are pioneer in the field of heterogeneous catalysts for fine chemical synthesis their contribution is highly appreciated.
Mechanism of estragole isomerization with hydrotalcite catalyst:

Reaction pathway is designed by Kanan [6] one can say that strong Lewis basic sites $\left(\mathrm{O}^{2-}\right)$ derived from the calcination of hydrotalcites, may not be appropriate for enabling estragole isomerization while Bronsted basic hydroxyls (hydroxylated layered network) are the active centers, which abstract proton of methylene carbon in facilitating the isomerization. A probable mechanistic pathway for isomerization of estragole over $\mathrm{Mg}$ - $\mathrm{Al}$ binary hydrotalcite is depicted in Scheme 1.

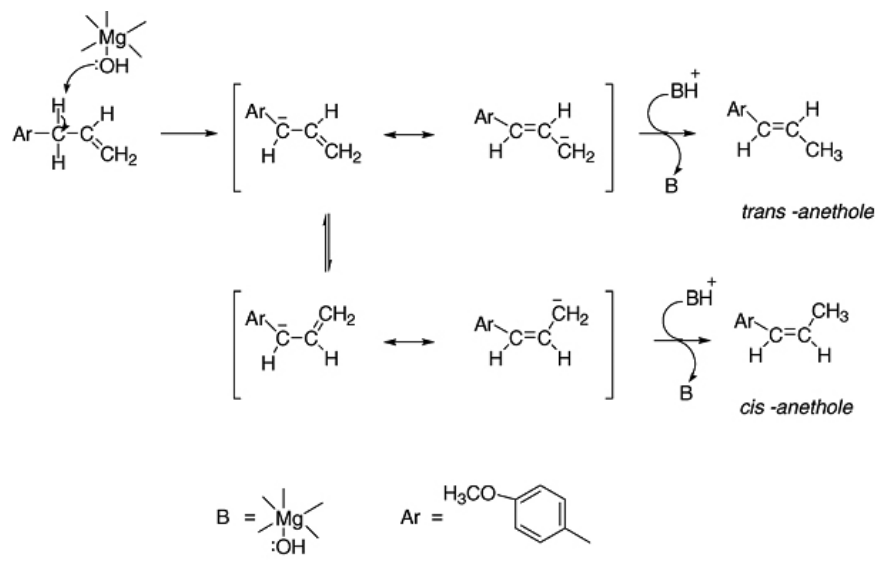

Scheme 1

2. Experimental Section:

2.1 Preparation of Ni-Al hydrotalcite (Ni/Al, 2:1) [Cat A]

The catalysts were prepared by coprecipitation method and taking appropriate ratios of $\mathrm{Ni}$ and $\mathrm{Al}$ nitrates $[7,8]$.

2.2 Preparation of Calcined Ni-Al hydrotalcite ( $\mathrm{Ni} / \mathrm{Al}, 2: 1)$ [Cat $\mathrm{A}]$ : The same procedure is repeated with ratio being changed [7-8]

\section{RESULTS AND DISCUSSION}

\subsection{Catalysts Characterization:}

XRD of Hydrotalcites:

The XRD for LDHs samples such as carbonates which have one unit hexagonal cell as shown in Fig. 1. The peak at $11.5^{\circ} 2 q(d$ spacing $=7.7 \AA)$ of hydrotalcite carbonate was attributed to the reflections from the (003) family of crystallographic planes. These planes are spaced one-third per unit cell distance apart and these corresponds to the interlayer distance [23] studied by Carlino. The $\mathrm{d}$ spacing is known as the interlayer spacing which is formed from the metal hydroxide sheet (approximately $4.8 \AA$ ) and the gallery region is around $2.8 \AA$ that contains the intercalated anions. This gallery between the metal hydroxide layers is known as the interlayer distance or gallery height. The XRD samples 
of calcined at $723 \mathrm{~K}$ mainly shows the presence of mixed cubic oxide phases, which is obtained by the loss of water and carbon dioxide from the anionic interlayer of hydrotalcite precursors. Ni-Al 2:1, 2.5:1, 3:1 hydrotalcite shows the characteristic crystalline pattern explained above which shows excellent activity for oxidation of alcohols with Ni-Al HT with molecular oxygen [7]. The used catalysts retained similar hydrotalcite XRD pattern. The XRD of the Ni-Al hydrotalcite calcined (Cat A) shows formation of NiO phase only with $\mathrm{Al}(\mathrm{III})$ inside. When the catalysts were rehydrated for 2 days at room temperature, the calcined sample could not be restructured into hydrotalcite [78]. These results are in good agreement with the reported data that restructured calcined $\mathrm{Ni}-\mathrm{Al}$ hydrotalcite requires stringent conditions [16-17,24].

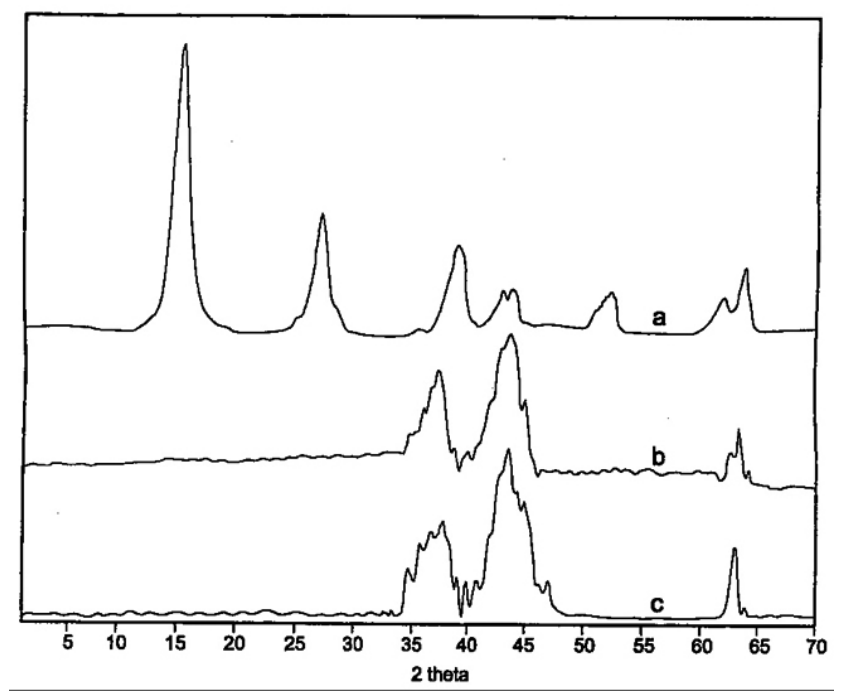

Figure 1. XRD powder patterns of samples. (a) $\mathrm{Ni}-\mathrm{Al}_{-}-\mathrm{CO}_{3}$ as-synthesised, (b) calcined Ni-Al hydrotalcite catalyst (cat A) and (c) used Cat A [8].

\section{Infrared Spectroscopy of Hydrotalcites:}

The infrared spectra for the hydrotalcites hydroxy stretching vibrations of $\mathrm{Ni}-\mathrm{Al}$ hydrotalcite [Cat. A (Ni:Al 2:1)] and Ni-Al hydrotalcite (Ni:Al 3:1) are shown in Fig. 2. The IR spectra of MgAlCO hydrotalcite, with different M(II) cations and Ni-Al hydrotalcites showed the absorption at $3500-3600 \mathrm{~cm}^{-1}$, which is attributed to the $\mathrm{H}$-bonding stretching vibrations of the $\mathrm{OH}$ group that is present in the brucite like sheets. Mostly the shifting of this bond depends upon the $\mathrm{x}$ for $\mathrm{Mg}(\mathrm{OH})_{2}$. When $\mathrm{X}=0$ the aborption of this band shifts to higher frequency of $3700 \mathrm{~cm}^{-1}$. Cavani et al $[25]$ reported that as the $\left(\mathrm{M}^{2+} / \mathrm{M}^{3+}\right)$ ratio increases the hydrogen stretching \& bending corroborated with the changes in the layer spacing. A shoulder is present around $3000 \mathrm{~cm}^{-1}$, is mainly attributed to hydrogen bonding between $\mathrm{H}_{2} \mathrm{O}$ and the anion in the interlayer $[16,25]$ and $\mathrm{H}_{2} \mathrm{O}$ bending vibration which occurs at $1600 \mathrm{~cm}^{-1}$. In most hydrotalcites [25] the three bands appears at $1350-1380 \mathrm{~cm}^{-1}\left(\mathrm{v}_{3}\right), 850-880 \mathrm{~cm}^{-1}\left(\mathrm{v}_{2}\right)$, and $670-$ $690 \mathrm{~cm}^{-1}$. The IR spectra of various compositions of Ni-Al hydrotalcite shows that the vibrational stretching frequency of the hydrogen atom in hydroxide group of Cat A with 2:1 Ni-Al ratio appears at lower wavelength $3420 \mathrm{~cm}^{-1}$ and has a smaller half width than the other compositions which indicates there is a more ordered cation distribution in the former [7-8].

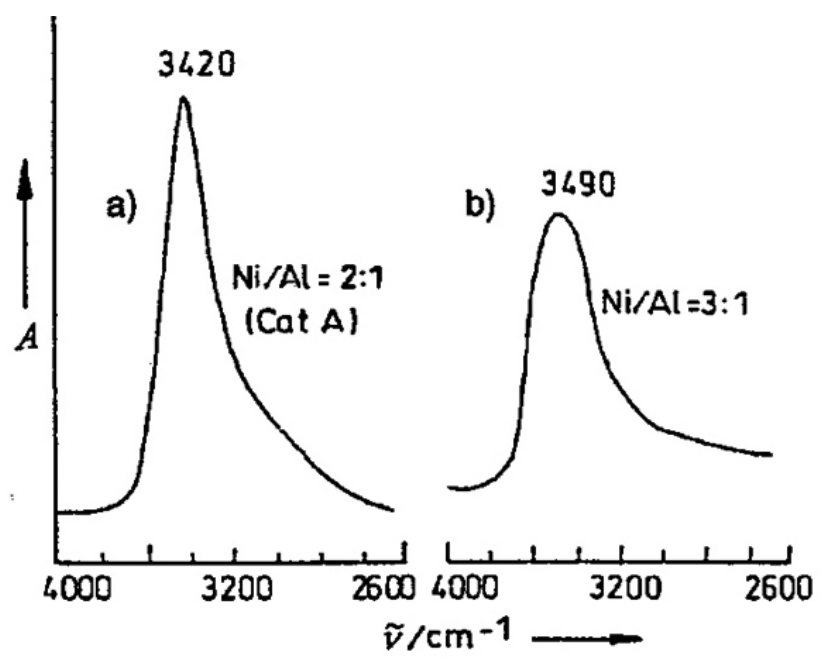

Figure 2. Hydroxy stretching vibrations of a) Ni-Al hydrotalcite, Cat. A (Ni:Al 2:1) and b) Ni-Al hydrotalcite (Ni:Al 3:1) [7].

\section{TPR Characterization:}

TPR studies are used for the characterization of the heterogeneous catalytic systems and are shown in Fig. 3. The TPR profile of hydotalcite indicates that free $\mathrm{NiO}$ is reduced at lower temperature and the $\mathrm{NiO}$ in association with oxide of aluminium is reduced at higher temperatures and ammonia display both free $\mathrm{NiO}$ and $\mathrm{NiO}$ in association with oxide of aluminium nickel aluminium hydrotalcite displays a shoulder at lower temperature that grows on free nickel oxide content. These TPR results are in good agreement with the results reported by Choudary et al [7]. The TPR samples of $\mathrm{Ni} / \gamma-\mathrm{Al}_{2} \mathrm{O}_{3}$ indicate the presence of free $\mathrm{NiO}$ only. The catalysts are prepared with ammonia method, displays both free $\mathrm{NiO}$ and $\mathrm{NiO}$ in association with aluminium oxide. The TPR for nickel containing hydrotalcite was studied for $\mathrm{Mg}-\mathrm{Ni}$ of varying ratios, showed two peaks of $\mathrm{H}_{2}$ consumption. The first peak around $570 \mathrm{~K}$ corresponds to the release of $\mathrm{NO}_{3}$ anions as $\mathrm{NO}_{2}$ and the subsequent reduction of $\mathrm{NO}$ and $\mathrm{N}_{2} \mathrm{O}$. The second peak with maxima at 705,920 and $1000 \mathrm{~K}$ for respective samples to the reduction of $\mathrm{NiO}$ particles. When $\mathrm{Mg}$ content is increased the reduction of the nickel oxide decreases it can be compared with the decrease of the $\mathrm{NiO}$ crystal size. This behaviour is attributed to the formation of $\mathrm{Ni}$ aluminate band of nickel spinel type and decreasing the size the crystallite and hence it hinders their reducibility [26-31]. The excellent results of these catalysts from characterization studies guide us to investigate for high activity of these catalysts Ni-Al 2:1 for the bromination of $\beta$-ketoester at $\alpha$-positon with N-bromosuccinimide as brominating agent. The conversions were $65 \%$ with high selectivity. Whereas, with the Ni-Al 2.5:1 the conv was $60 \%$ and with $3: 1$ the conv was $57 \%$. The less conv activity of $\mathrm{Ni}-\mathrm{Al} 2.5: 1$ and $3: 1$ were due to high nickel content [32] present, but with high selectivity retained. 


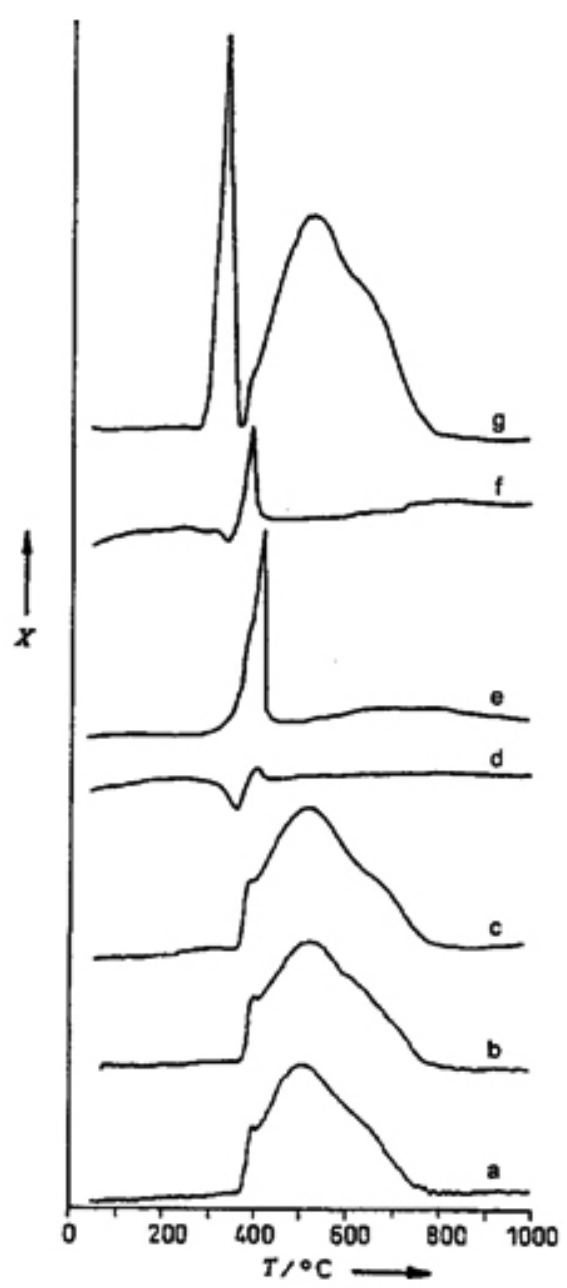

Figure 3 TPR profiles plotted as amount of hydrogen consumed ( $\mathrm{x}$ is arbitrary units) versus temperatures $\left[{ }^{\circ} \mathrm{C}\right]$ of a) Ni-Al hydrotalcite (cat A) b) Ni-Al hydrotalcite (Ni: Al 2.5:1), c) b) Ni-Al hydrotalcite (Ni: Al 3:1) d) Ni$\gamma-\mathrm{Al}_{2} \mathrm{O}_{3} 2 \%$

e) $\mathrm{Ni}-\gamma-\mathrm{Al}_{2} \mathrm{O}_{3} 5 \%$ f) $\mathrm{Ni}-\gamma-\mathrm{Al}_{2} \mathrm{O}_{3} 10 \%$, g) Ni-Al Cat B [7].

\section{CONCLUSIONS}

In conclusion $\mathrm{Ni}$ hydrotalcites have been characterized by XRD, IR and TPR results which confirms that nickel hydrotalcites are active catalysts for oxidation of alcohols, alkyl aromatics, epoxidation of olefins, sulphur oxidation and reduction, reactions, our group is involved in studying organic transformations such as Aldol, Micheal, Knoevenegal, oxidation of alcohols, dihyroxylation of olefins, bromination of bis-phenol-A with $\mathrm{Ni}$ containing hydrotalcites. The excellent results of these catalysts from characterization studies guide us to investigate the high activity in bromination of $\beta$-ketoester at $\alpha$-positon for organic transformations.

\section{ACKNOWLEDGEMENTS}

The authors extend their appreciation to the deanship of scientific research at king saud university for funding the work through the research group project No RGP-VPP-089.

\section{REFERENCES}

[1] F.J. Brocker and L. Kainer, German Patent 2024 282, 1970 to BASF AG, and UK Patent 1,342,020 197, to BASF AG.

[2] E. Manasse, Atti. Soc. Toscana Sc. Nat., Proc. Verb., 1915, 24, 92.

[3] R. Allman, Chimia. 1970, 24, 99.

[4] S. Miyata and A. Okada, US pat., 4351 814, 1982.
[5] C. P. Kelkar and A. A. schutz, Microporous Mater., 1997, 10, 163.

[6a] S. Kannan Catalysis Surveys from Asia 2006,10, 117 b. Dyes and Pigments, Pinggui Tang, Yongjun Feng, Dianqing Li (In press) 2011.

c. N. Benselka-Hadj Abdelkader, A. Bentouami, Z. Derriche, N. Bettahar, L-C de Ménorval Chemical Engineering Journal, 2011 (In Press).

[7a] B.M. Choudary, M. L. Kantam, Ateeq Rahman, Ch. V. R. Reddy and K. Koteshwar Rao Angew. Chem. Intl. Ed. 2001, 40, 763.

b. Tomohito Kameda, Hidenori Takeuchi, Toshiaki Yoshioka J. Phy and Chem Solids, 2011 (In press).

[8] B.M. Choudary, M. L. Kantam, Ateeq Rahman and Ch. V. R. Reddy J. Mol. Cat. 2003, 206, 145.

[9] M. L. Kantam, B. Kavita, Ateeq Rahman and M. Sateesh, Indian Journal of Chemistry Sect. B 1998, 37, 1039.

[10] B.M. Choudary, M. L. Kantam, B. Bharathi, and Ch. V. R. Reddy, Synlett, 1998, 1203

[11] B.M. Choudary, M. L. Kantam, B. Kavitha, C. V. Reddy, K. Koteshwar Rao and F. Figuiras, Tetrahedron Lett., 1998, 39, 3555.

[12a] B.M. Choudary, M. L. Kantam, and B. Kavitha, Green Chem.,1999, 1, 289.

b. O.D. Pavel, R. Zăvoianu, R. Bîrjega, E. Angelescu Catal Commun, 2011, 845 .

[13] B.M. Choudary, M. L. Kantam, and B. Kavitha, C. V. R. Reddy and F. Figuiras, Tettrahedron, 2000, 56, 9357.

[14] B.M. Choudary, M. L. Kantam, C. V. R. Reddy and S. Aranganathan, P. L. Shanthi and F. Figueras, J. Mol. Cat. A: Chem., 2000, 159, 411.

[15] T. Kwon and T. J. Pinnavaia, J. Mol. Cat. 1992, 74, 23.

[16] O. Clause, B. Rebours, E. Merlen, F. Trifiro and A. Vaccari, J. Catal. 1992, 133, 231.

[17] B.M. Choudary, T. Someshwar, Ch. Venkat Reddy, M. L. Kantam, K. Jeevaratnam and L.V. Sivaji, Appl. Catal. A Gen. 2003, 251, 397.

[18] B.M. Choudary, N. S. Chowdari, K. Jyoti and M. L. Kantam, J. Am. Chem. Soc. 2002, 124, 5341.

[19] S. Kannan, Catalysis Surveys from Asia. 2006, 10, 117.

[20] W. T. Reichle, J. Catal. 1985, 94, 547.

[21] M. L. Kantam, B.M. Choudary, C. V. Reddy, K. Koteshwar Rao and F. Figuiras, Chem. Commun. 1998, 1033.

[22] E. C. Kruissink and L. L. van Reijen, J. Chem. Soc. Faraday Trans. 1981, $77,649$.

[23] S. Carlino, Chem. Ber 1997, 59.

[24] B. Rebours, J.B. d' Espinose de la Caillerie and O. Clause, J. Am. Chem. Soc. 1994, 116, 1707.

[25] F. Cavani, F. Trifiro and A. Vaccari, Catal. Today 1991, 11, 173.

[26] D. L. Bisch and G. W. Brindley, Amer. Min. 1977, 62, 458.

[27] S. Miyata, Clay \& Clay Miner. Mag. 1975, 23, 369.

[28] G.Fornasari, M.Gazzano, D.Matteuzzi, F.Trifiro and A.Vaccari, Appl. Clay Science 1995, 10, 69.

[29] N.I. Chikuri, D.Murata, S. Schmazu and T. Uematsu, Cat. Lett. 2000, 69, 33.

[30] D. Tichit, F. Medina, B. Coq and R. Dutarte, Appl. Catal. A: 1997, 159, 241.

[31] J. Hu, J. A. Schwarz and Y.-J. Huang, Appl. Catal. 1989, 51, 223.

[32a.] Ateeq Rahman and S. B. Jonnalagadda, Cat. Lett., 2008, 31, 164.

b. Ateeq Rahman and S B Jonnalagadda J Mol. Cat A: 299, 2009, 99. c. Ateeq Rahman, P.V.S.R Rajasekhar Pullabhotla and S B Jonnalagadda. Cat. Commun 9, 2008, 2417. 